Article

\title{
Systemic Oxygen Delivery during One-Lung Ventilation: Comparison between Propofol and Sevoflurane Anaesthesia in a Randomised Controlled Trial
}

\author{
Tae Soo Hahm ${ }^{\dagger}$, Heejoon Jeong ${ }^{\dagger}$ and Hyun Joo Ahn *(D) \\ Department of Anaesthesiology and Pain Medicine, Samsung Medical Center, Sungkyunkwan University \\ School of Medicine, Seoul 06351, Korea; ts.hahm@samsung.com (T.S.H.); heejoon.jeong@samsung.com (H.J.) \\ * Correspondence: hyunjooahn@skku.edu; Tel.: +82-2-3410-0784; Fax: +82-2-3410-2461 \\ + These authors contributed equally to this work.
}

Received: 25 July 2019; Accepted: 9 September 2019; Published: 11 September 2019

\begin{abstract}
Systemic oxygen delivery $\left(\mathrm{DO}_{2}\right)$ is a more comprehensive marker of patient status than arterial oxygen saturation $\left(\mathrm{SaO}_{2}\right)$, and $\mathrm{DO}_{2}$ in the range of $330-500 \mathrm{~mL} \mathrm{~min}^{-1}$ is reportedly adequate during anaesthesia. We measured $\mathrm{DO}_{2}$ during one-lung ventilation $(\mathrm{OLV})$ for thoracic surgery-where the risk of pulmonary shunt is significant, and hypoxia occurs frequently-and compared sevoflurane and propofol, the two most commonly used anaesthetics in terms of $\mathrm{DO}_{2}$. Sevoflurane impairs hypoxic pulmonary vasoconstriction. Thus, our hypothesis was that propofol-based anaesthesia would show a higher $\mathrm{DO}_{2}$ value than sevoflurane-based anaesthesia. This was a double-blinded randomised controlled trial conducted at a university hospital from 2017 to 2018. The study population consisted of patients scheduled for lobectomy under OLV $(N=120)$. Sevoflurane or propofol was titrated to a bispectral index of 40-50. Haemodynamic variables were measured during two-lung ventilation (TLV) and OLV at 15 and $45 \mathrm{~min}$ (OLV15 and OLV45, respectively) using oesophageal Doppler monitoring. The mean $\mathrm{DO}_{2}\left(\mathrm{~mL} \mathrm{~min}^{-1}\right)$ was not different between the sevoflurane and propofol anaesthesia groups (TLV: 680 vs. 706; OLV15: 685 vs. 703; OLV45: 759 vs. 782, respectively). $\mathrm{SaO}_{2}$ was not correlated with $\mathrm{DO}_{2}(\mathrm{r}=0.09, p=0.100)$. Patients with $\mathrm{SaO}_{2}<94 \%$ showed adequate $\mathrm{DO}_{2}\left(641 \pm 203 \mathrm{~mL} \mathrm{~min}^{-1}\right)$, and patients with high $\mathrm{SaO}_{2}(>97 \%)$ showed inadequate $\mathrm{DO}_{2}(14 \%$ of measurements $<500 \mathrm{~mL} \mathrm{~min}^{-1}$ ). In conclusion, $\mathrm{DO}_{2}$ did not significantly differ between sevoflurane and propofol. $\mathrm{SaO}_{2}$ was not correlated with $\mathrm{DO}_{2}$ and was not informative regarding whether the patients were receiving an adequate oxygen supply. $\mathrm{DO}_{2}$ may provide additional information on patient status, which may be especially important when patients show a low $\mathrm{SaO}_{2}$.
\end{abstract}

Keywords: Delivery of oxygen; one-lung ventilation; propofol; sevoflurane; thoracic anaesthesia

\section{Introduction}

The concept of systemic delivery of oxygen $\left(\mathrm{DO}_{2}\right)$ is attracting increasing interest in both the context of anaesthesia [1] and the intensive care unit (ICU) [2-4]. $\mathrm{DO}_{2}$ is calculated as: (haemoglobin $\times$ $\left.1.34 \times \mathrm{SaO}_{2}+\mathrm{PaO}_{2} \times 0.003\right) \times$ cardiac output $\times 10$. It is, thus, a more comprehensive (and important) marker of patient status than arterial oxygen saturation $\left(\mathrm{SaO}_{2}\right)$ [5], being based on haemoglobin, oxygen saturation, and cardiac output.

Normal $\mathrm{DO}_{2}$ in awake, healthy, subjects is $1000 \mathrm{~mL} \mathrm{~min}^{-1}$ at rest, while $\mathrm{O}_{2}$ consumption $\left(\mathrm{VO}_{2}\right)$ is $250 \mathrm{~mL} \mathrm{~min}^{-1}$ [5]. A target $\mathrm{DO}_{2}$ of $330[6]$ or $500 \mathrm{~mL} \mathrm{~min}^{-1}[7,8]$ has been suggested for preventing tissue $\mathrm{O}_{2}$ deprivation under anaesthesia. 
There is a significant risk of pulmonary shunt and hypoxia during one-lung ventilation (OLV) in thoracic surgery. Sevoflurane and propofol, the two most common anaesthetics, have been compared in terms of $\mathrm{SaO}_{2}$, but not in terms of $\mathrm{DO}_{2}$, during OLV [9].

These anaesthetics may show different associations with $\mathrm{DO}_{2}$, based on their differential effects on $\mathrm{SaO}_{2}$ and cardiac output (which are the major determinants of $\mathrm{DO}_{2}$ ). Inhalation anaesthetics, including sevoflurane, are thought to reduce hypoxic pulmonary vasoconstriction $[10,11]$, thereby increasing the 'shunting' of nonoxygenated blood during OLV and, thus, causing lower $\mathrm{SaO}_{2}$ [12]. Notably, lower $\mathrm{SaO}_{2}$ can decrease $\mathrm{DO}_{2}$. It is not clear whether sevoflurane or propofol yields a higher cardiac output [13-16]. Therefore, in the present study, we measured $\mathrm{DO}_{2}$ in patients undergoing thoracic surgery with OLV and compared differences therein between sevoflurane- and propofol-based anaesthesia. We hypothesised that sevoflurane-based anaesthesia would be associated with a lower $\mathrm{DO}_{2}$ than propofol-based anaesthesia. The secondary outcome was the relationship between $\mathrm{SaO}_{2}$ and $\mathrm{DO}_{2}$.

\section{Experimental Section}

This prospective, randomised study was approved by the Institutional Review Board of Samsung Medical Center, Chairperson Prof. Suk-Koo Lee, Seoul, Korea (IRB file number: SMC 2017-06-069-003, IRB approval: 2017-09-05) and registered prior to patient enrolment at the Clinical Research Information Service (KCT0002782; Principal investigator, Tae Soo Hahm; date of first submission, 20 September 2017; date of registration of first patient, 25 September 2017; https://cris.nih.go.kr/cris). Written informed consent was obtained from all participants.

\subsection{Study Population}

This study was performed between September 2017 and July 2018 at the Samsung Medical Center (Seoul, Korea). During the study period, a total of 144 patients were assessed for eligibility by study staff, and 139 patients were enrolled in the study.

The inclusion criteria were age $\geq 19$ years, American Society of Anaesthesiologists physical status I-III, and elective pulmonary lobectomy under open thoracotomy or video-assisted thoracoscopic surgery (VATS). Cases requiring at least $1 \mathrm{~h}$ of OLV were included. The exclusion criteria were forced expiratory volume in $1 \mathrm{~s}\left(\mathrm{FEV}_{1}\right)<40 \%$ of predicted value, cardiac ejection fraction $<50 \%$, recent oesophageal surgery or presence of congenital or acquired oesophageal abnormalities (stricture, varices, or fistula), and haemoglobin $<10 \mathrm{~g} \mathrm{dL}^{-1}$. Patients who did not understand the study objectives or refused to participate were excluded. Dropout criteria included OLV $<1 \mathrm{~h}$, protocol interruption for rescue ventilation $\left(\mathrm{SpO}_{2}<90 \%\right)$, bleeding $>400 \mathrm{~mL}$, sampling/measurement error, and inotrope or vasopressor administration during measurement.

\subsection{Randomisation and Blinding Procedure}

Patients were randomised into sevoflurane and propofol groups by computer-generated random numbers with a fixed block size of 4 and a 1:1 ratio, and patient allocations were sealed in an opaque envelope. An attending anaesthesiologist who was not involved in the study opened the sealed envelope just before induction of anaesthesia and provided the designated anaesthetic agents according to the group assignment. Oesophageal Doppler monitoring was performed by a single designated anaesthesiologist who was not involved in the study, while vaporiser, gas monitor, and drug infusion pumps were hidden by an opaque screen. The corresponding author and co-authors collected data by retrieving blinded study logs. Attending anaesthesiologists were not blinded to the patients' group assignment, but they were not involved in patient allocation or data analysis.

\subsection{Intraoperative Management}

No premedication was given before induction of anaesthesia. After the patient arrived at the operation room, electrocardiography, a non-invasive blood pressure cuff, pulse oximetry, and bispectral index (BIS) monitor (v. 4.0; Aspect Medical Systems, Natick, MA, USA) were applied. 
For induction of anaesthesia, a bolus of $1.5-2.5 \mathrm{mg} \mathrm{kg}^{-1}$ propofol with continuous remifentanil infusion $\left(0.05 \mu \mathrm{g} \mathrm{kg}^{-1} \mathrm{~min}^{-1}\right)$ was used. During surgery, anaesthesia was maintained with sevoflurane or propofol. Propofol was administered using an infusion pump in the range of $80-120 \mu \mathrm{g} \mathrm{kg}^{-1}$ $\mathrm{min}^{-1}$. The attending anaesthesiologist titrated sevoflurane or propofol to maintain the BIS index between 40 and 50 . Remifentanil $\left(0.05 \mu \mathrm{g} \mathrm{kg}^{-1} \mathrm{~min}^{-1}\right)$ and rocuronium were continuously infused in both groups. Bolus administration of remifentanil $\left(0.3 \mu \mathrm{g} \mathrm{kg}^{-1}\right)$ was used for intubation and during intensive surgical stimulation.

Intubation was performed using a double-lumen tube after $1.0 \mathrm{mg} \mathrm{kg}^{-1}$ rocuronium bolus injection, and the position of the tube was confirmed by fibreoptic bronchoscopy. A radial arterial catheter was placed on the opposite side of surgery. After induction, the oesophageal Doppler probe (CardioQ; Deltex Medical, Irving, TX, USA) was inserted through the oropharynx into the distal oesophagus, approximately $35-50 \mathrm{~cm}$ from the incisors. Ringer's solution was used as the maintenance fluid and was infused at $3-5 \mathrm{~mL} \mathrm{~kg}^{-1} \mathrm{~h}^{-1}$.

All patients received the same ventilation protocol, which was tidal volume of $6-8 \mathrm{~mL} \mathrm{~kg}^{-1}$ predicted body weight with $5 \mathrm{cmH}_{2} \mathrm{O}$ of positive end-expiratory pressure during two-lung ventilation (TLV) under volume-controlled mode. Tidal volume decreased to $5-6 \mathrm{~mL} \mathrm{~kg}^{-1}$ predicted body weight during OLV. The ventilation rate was adjusted to maintain end-tidal carbon dioxide at $35-40 \mathrm{mmHg}$. $\mathrm{FIO}_{2}$ was maintained at $100 \%$ throughout the study period and was decreased to $50 \%$ thereafter. The operation was performed in the lateral decubitus position with the operated side up. OLV was started when the patient was turned to the lateral decubitus position in VATS or when the fascia was incised during open thoracotomy. All patients were extubated upon meeting the extubation criteria and transferred to the ICU after anaesthesia recovery at the post-anaesthetic care unit.

\subsection{Measurements}

Haemodynamic measurements and arterial blood gas analyses were conducted during TLV in the lateral position immediately before OLV (TLV) and at 15 and $45 \mathrm{~min}$ after the initiation of OLV (OLV15 and OLV45, respectively). Stable heart rate and mean arterial pressure were observed for $10 \mathrm{~min}$ before haemodynamic measurements without application of vasopressors/inotropes.

Doppler monitoring was performed at TLV, OLV15, and OLV45 by the designated anaesthesiologist. The oesophageal Doppler probe was manipulated with adjustment of depth and rotational position until the characteristic descending thoracic aortic waveform shape was visualised and the distinctive Doppler 'whip crack' sound associated with aortic blood flow was heard. The best three waveforms were stored, and the averaged values were used for determination of cardiac output.

The CardioQ and an oesophageal Doppler monitor system continuously monitored stroke volume and cardiac output without external calibration. Stroke volume was calculated as the product of the velocity-time integral, and a calibration factor was derived from a nomogram based on each patient's age, height, and weight. $\mathrm{DO}_{2}$ was calculated as: (haemoglobin $\times 1.34 \times \mathrm{SaO}_{2}+\mathrm{PaO}_{2} \times 0.003$ ) $\times$ cardiac output $\times 10$. Alveolar $\mathrm{O}_{2}$ pressure $\left(\mathrm{PAO}_{2}\right)$ was calculated under the high $\mathrm{FIO}_{2}$ condition as: $\mathrm{FIO} 2 \times$ $\left(\mathrm{P}_{\mathrm{b}}-\mathrm{P}_{\mathrm{H} 2 \mathrm{O}}\right)-\mathrm{PACO}_{2}=\mathrm{FIO}_{2} \times(760-47)-\mathrm{PACO}_{2}$.

\subsection{Statistical Analysis}

The primary endpoint was the difference in $\mathrm{DO}_{2}$ between the two anaesthetic groups. The secondary endpoint was the correlation between $\mathrm{SaO}_{2}$ and $\mathrm{DO}_{2}$. Power analysis showed that a difference in $\mathrm{DO}_{2}$ of $150 \mathrm{~mL} \mathrm{~min}^{-1}$ between the sevoflurane and propofol groups could be regarded as significant. The standard deviation (SD) of each anaesthetic was obtained from previous studies conducted during the induction periods (sevoflurane, $72 \mathrm{~mL} \mathrm{~min}^{-1}$; propofol, $336 \mathrm{~mL} \mathrm{~min}^{-1}$ ). Assuming a similar reduction and a $20 \%$ dropout rate, 120 patients were required for a two-sided alpha of $5 \%$ with $80 \%$ power (independent $t$ test).

Continuous variables are presented as the mean $\pm \mathrm{SD}$ or median (interquartile range). Categorical variables are presented as counts (\%). The $\mathrm{DO}_{2}$, cardiac output, $\mathrm{PaO}_{2} / \mathrm{FIO}_{2}$, alveolar arterial $\mathrm{O}_{2}$, and blood lactate were compared between the two groups using the independent $t$ test or Mann-Whitney 
test depending on the data distribution. Comparisons between variables at each time point were performed using repeated-measures ANOVA. The Bonferroni correction was performed for multiple testing. The normality of the distribution of the data was evaluated with the Shapiro-Wilk test. Confidence intervals for non-normally distributed variables were calculated using the Hodges-Lehmann estimator. All $p$-values were two-sided, and $p<0.05$ was taken to indicate statistical significance. Data were analysed using MedCalc for Windows (ver. 7.3; MedCalc Software, Mariakerke, Belgium) and SPSS software (ver. 25.0; IBM Corp., Chicago, IL, USA).

\section{Results}

A total of 144 patients were assessed for eligibility. Four patients refused to participate, and one surgery was cancelled; therefore, 139 patients were enrolled in the study. Six patients dropped out because of measurement error or missing data. One patient was converted to open-and-close surgery. OLV did not last $1 \mathrm{~h}$ in two patients. Ten patients required intervention for rescue ventilation due to hypoxia $\left(\mathrm{SpO}_{2}<90 \%\right)$. There were no cases with significant intraoperative blood loss $(>400 \mathrm{~mL})$. No vasopressors/inotropes were administered during the haemodynamic measurement. Finally, 60 patients in each group (sevoflurane and propofol) were included in the analysis (Figure 1).

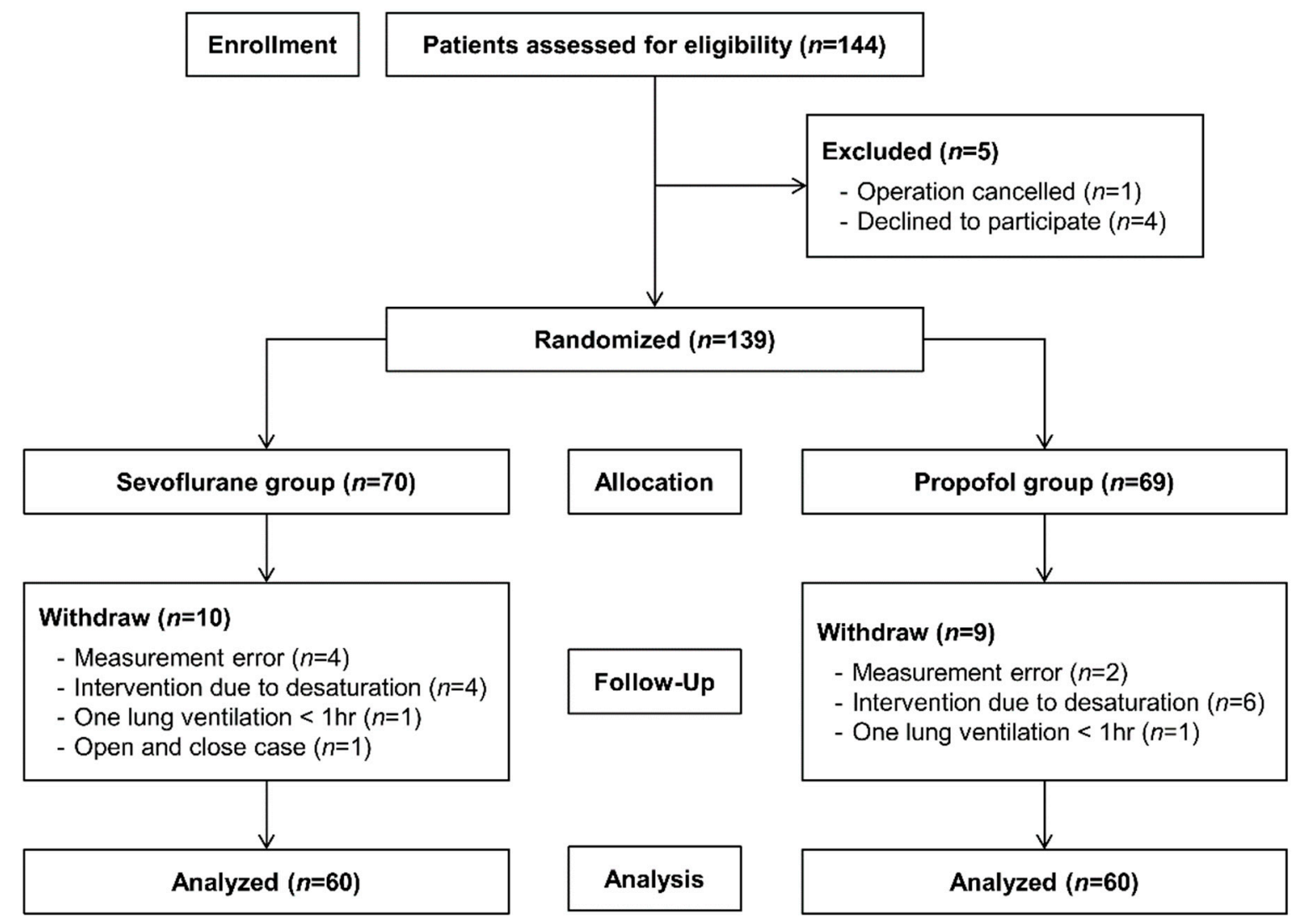

Figure 1. Flow diagram of patient selection.

In comparisons between the two anaesthesia groups, there were no differences in baseline demographic or operational characteristics (Table 1) 
Table 1. Characteristics of patients between sevoflurane and propofol groups.

\begin{tabular}{|c|c|c|}
\hline Characteristics & $\begin{array}{l}\text { Sevoflurane Group } \\
(n=60)\end{array}$ & $\begin{array}{c}\text { Propofol Group } \\
(n=60)\end{array}$ \\
\hline Age (year) & $64(57-71)$ & $62(55-68)$ \\
\hline Male & $37(61.7)$ & $36(60.0)$ \\
\hline Body mass index $\left(\mathrm{kg} / \mathrm{m}^{2}\right)$ & $24(22-26)$ & $24(21-25)$ \\
\hline ASA physical status, $1 / 2 / 3$ & $29 / 23 / 8$ & $25 / 28 / 7$ \\
\hline Haemoglobin (g/dL) & $13.5(12.4-14.4)$ & $13.2(12.5-15.0)$ \\
\hline Albumin (g/dL) & $4.5(4.2-4.8)$ & $4.5(4.2-4.7)$ \\
\hline History of previous lung surgery & $3(5)$ & $2(3)$ \\
\hline Smoking & $7(12)$ & $3(5)$ \\
\hline Hypertension & $18(30)$ & $16(27)$ \\
\hline Diabetes mellitus & $11(18)$ & $6(10)$ \\
\hline \multicolumn{3}{|l|}{ Pulmonary comorbidities } \\
\hline Recent respiratory infection & $3(5)$ & $1(2)$ \\
\hline History of pulmonary tuberculosis & $1(2)$ & $2(3)$ \\
\hline COPD & $2(3)$ & $2(3)$ \\
\hline Bronchiectasis & $0(0)$ & $3(5)$ \\
\hline Cardiac disease & $3(5)$ & $4(7)$ \\
\hline Liver disease & $7(12)$ & $9(15)$ \\
\hline Renal disease & $4(7)$ & $4(7)$ \\
\hline $\begin{array}{l}\text { Previous chemotherapy and } \\
\text { radiotherapy }\end{array}$ & $5(8)$ & $4(7)$ \\
\hline Surgery, Open/VATS & $12 / 48$ & $13 / 47$ \\
\hline Ventilation site, Left/Right & $40 / 20$ & $46 / 14$ \\
\hline Duration of surgery (min) & $126(93-157)$ & $124(100-158)$ \\
\hline Anaesthesia time (min) & $176(142-225)$ & $176(147-202)$ \\
\hline Duration of one lung ventilation (min) & $100(73-146)$ & $101(78-128)$ \\
\hline Intraoperative fluid amount (mL) & $900(650-1150)$ & $925(750-1150)$ \\
\hline Intraoperative blood loss (mL) & $100(50-187)$ & $100(50-150)$ \\
\hline Bispectral index & $45 \pm 3$ & $44 \pm 2$ \\
\hline
\end{tabular}

The data are presented as mean \pm standard deviation, median (interquartile range), or number (percentage). History of previous lung surgery included any kind of operation that invaded the pleural space. Smoking was defined as patients who kept smoking or stopped smoking within 1 month before surgery. Recent respiratory infection was defined as pulmonary infection within 1 month from surgery. Cardiac disease included any histories of angina and myocardial infarction. Renal disease was estimated with a glomerular filtration rate of $<60 \mathrm{~mL} \mathrm{~min}^{-1}$ $1.73 \mathrm{~m}^{2-1}$. COPD, chronic obstructive pulmonary disease; VATS, video-assisted thoracoscopic surgery.

$\mathrm{DO}_{2}$ was not different between the sevoflurane and propofol groups (TLV: $680 \mathrm{vs} .706 \mathrm{~mL} \mathrm{~min}^{-1}$, respectively; OLV15: 685 vs. $703 \mathrm{~mL} \mathrm{~min}^{-1}$, respectively; OLV45: 759 vs. $782 \mathrm{~mL} \mathrm{~min}^{-1}$, respectively; all, $p>0.05$ ) (Table 2, Figure 2) and increased with time. There was no difference in $\mathrm{SaO}_{2}$ between the sevoflurane and propofol groups (TLV: $98.8 \%$ vs. $98.8 \%$, respectively; OLV15: $97.7 \%$ vs. $97.8 \%$, respectively; OLV45: $97.4 \%$ vs. $97.8 \%$, respectively; all, $p>0.05$ ) (Table 2).

Table 2. Major haemodynamic variables.

\begin{tabular}{cccc}
\hline Variables & TLV & OLV 15 & OLV 45 \\
\hline $\mathrm{DO}_{2}(\mathrm{~mL} / \mathrm{min})$ & & & \\
Sevoflurane & $680 \pm 173$ & $685 \pm 209$ & $759 \pm 201$ \\
$\quad$ Propofol & $706 \pm 191$ & $703 \pm 208$ & $782 \pm 222$ \\
$\mathrm{SaO}_{2}(\%)$ & & & \\
$\quad$ Sevoflurane & $98.8 \pm 0.5$ & $97.7 \pm 2.0$ & $97.4 \pm 2.0$ \\
$\quad$ Propofol & $98.8 \pm 0.4$ & $97.8 \pm 1.8$ & $97.8 \pm 1.7$ \\
Stroke volume (mL) & & & \\
Sevoflurane & $54 \pm 15^{*}$ & $61 \pm 23$ & $62 \pm 22$ \\
$\quad$ Propofol & $60 \pm 14$ & $63 \pm 20$ & $70 \pm 24$ \\
\hline
\end{tabular}


Table 2. Cont.

\begin{tabular}{|c|c|c|c|}
\hline Variables & TLV & OLV 15 & OLV 45 \\
\hline \multicolumn{4}{|c|}{ Heart rate (per min) } \\
\hline Sevoflurane & $70 \pm 11$ & $71 \pm 11$ & $75 \pm 11$ \\
\hline Propofol & $68 \pm 12$ & $69 \pm 12$ & $71 \pm 13$ \\
\hline \multicolumn{4}{|c|}{ Mean arterial pressure $(\mathrm{mmHg})$} \\
\hline Sevoflurane & $85 \pm 14$ & $85 \pm 14$ & $81 \pm 11$ \\
\hline Propofol & $87 \pm 14$ & $87 \pm 14$ & $80 \pm 11$ \\
\hline \multicolumn{4}{|c|}{ Cardiac output (L/min) } \\
\hline Sevoflurane & $3.8 \pm 1.0$ & $4.0 \pm 1.2$ & $4.4 \pm 1.1$ \\
\hline Propofol & $3.9 \pm 1.0$ & $4.0 \pm 1.0$ & $4.5 \pm 1.1$ \\
\hline \multicolumn{4}{|c|}{ Haemoglobin (g/dL) } \\
\hline Sevoflurane & $12.6 \pm 1.2$ & $12.6 \pm 1.1$ & $12.6 \pm 1.2$ \\
\hline Propofol & $12.7 \pm 1.3$ & $12.7 \pm 1.5$ & $12.6 \pm 1.3$ \\
\hline \multicolumn{4}{|c|}{ Alveolar-arterial $\mathrm{O}_{2}$ difference $(\mathrm{mmHg})$} \\
\hline Sevoflurane & $181 \pm 92$ & $426 \pm 107$ & $366 \pm 146$ \\
\hline Propofol & $190 \pm 101$ & $418 \pm 105$ & $367 \pm 121$ \\
\hline \multicolumn{4}{|l|}{$\mathrm{PaO}_{2} / \mathrm{FIO}_{2}$} \\
\hline Sevoflurane & $483 \pm 88$ & $235 \pm 110$ & $244 \pm 133$ \\
\hline Propofol & $479 \pm 105$ & $249 \pm 108$ & $257 \pm 121$ \\
\hline \multicolumn{4}{|c|}{ Plasma lactate $(\mathrm{mmol} / \mathrm{L})$} \\
\hline Sevoflurane & $1.39 \pm 0.49$ & $1.40 \pm 0.53$ & $1.42 \pm 0.48^{\dagger}$ \\
\hline Propofol & $1.23 \pm 0.39$ & $1.23 \pm 0.37$ & $1.21 \pm 0.36$ \\
\hline \multicolumn{4}{|c|}{ Anion gap (mmol/L) } \\
\hline Sevoflurane & $11.4 \pm 1.8$ & $11.1 \pm 2.0$ & $11.1 \pm 2.5$ \\
\hline Propofol & $11.1 \pm 2.0$ & $10.9 \pm 1.9$ & $10.3 \pm 2.8$ \\
\hline
\end{tabular}

The data are presented as mean \pm SD. ${ }^{*} p=0.037$ and $^{\dagger} p=0.006$, compared to the propofol group. Bonferroni correction. $\mathrm{DO}_{2}$, oxygen delivery; $\mathrm{SaO}$, arterial oxygen saturation; $\mathrm{PaO}_{2}$, partial pressure of arterial oxygen; $\mathrm{FIO}_{2}$, fraction of inspired oxygen; TLV, two-lung ventilation; OLV, one-lung ventilation.

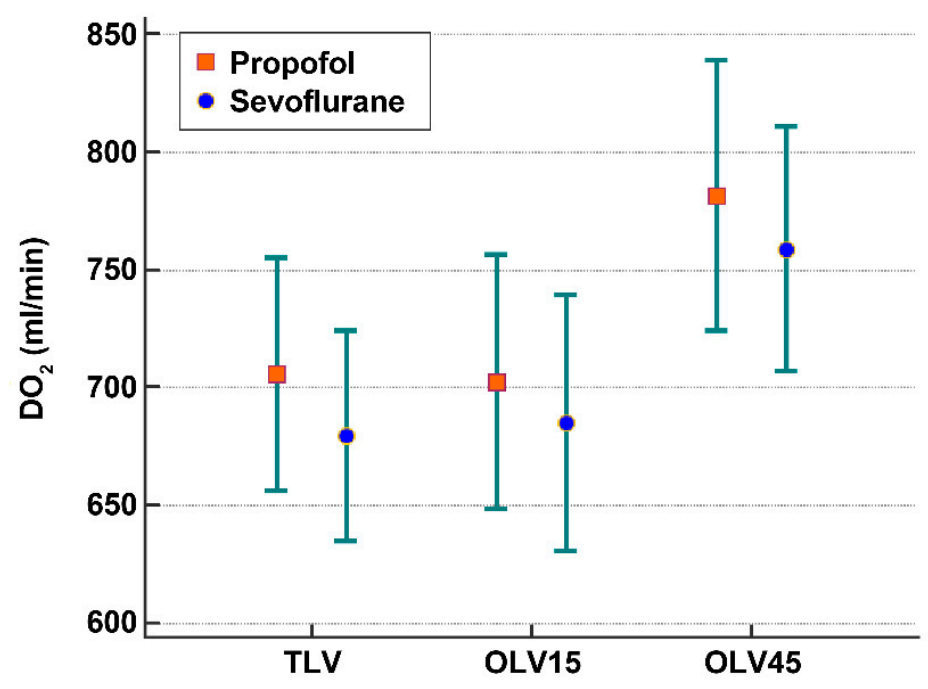

Figure 2. $\mathrm{DO}_{2}$ between sevoflurane and propofol in each time point. There was no difference in $\mathrm{DO}_{2}$ between the propofol and sevoflurane groups. $\mathrm{DO}_{2}$ increased with time. $p=0.0001$ between TLV and OLV45, $p=0.0001$ between OLV15 and OLV45, Bonferroni correction. TLV, two lung ventilation; OLV15, $15 \mathrm{~min}$ after initiation of one-lung ventilation; OLV45, $45 \mathrm{~min}$ after initiation of one-lung ventilation.

Stroke volume was higher in the propofol group (TLV: 54 vs. $60 \mathrm{~mL}, p=0.037$; OLV15: 61 vs. $63 \mathrm{~mL}, p=0.507$; OLV45: 62 vs. $70 \mathrm{~mL}, p=0.072$, for sevoflurane vs. propofol, respectively, Bonferroni correction). Heart rate and cardiac output (TLV: 3.8 vs. $3.9 \mathrm{~L} \mathrm{~min}^{-1}$; OLV15: 4.0 vs. $4.0 \mathrm{~L} \mathrm{~min}^{-1}$; OLV45: 4.4 vs. $4.5 \mathrm{~L} \mathrm{~min}^{-1}$, for sevoflurane vs. propofol, respectively) were not different between the two groups (Table 2). 
The alveolar-arterial $\mathrm{O}_{2}$ difference, which reflects pulmonary shunt, was not different between the two groups (TLV: 170 vs. $179 \mathrm{mmHg}$; OLV15: 413 vs. $405 \mathrm{mmHg}$; OLV45: 390 vs. $387 \mathrm{mmHg}$, for sevoflurane vs. propofol, respectively). $\mathrm{PaO}_{2} / \mathrm{FIO}_{2}$ was not different between the two groups (TLV: 483 vs. $479 \mathrm{mmHg}$; OLV15: 235 vs. $249 \mathrm{mmHg}$; OLV45: 244 vs. $257 \mathrm{mmHg}$, for sevoflurane vs. propofol, respectively).

The plasma lactate level was higher in the sevoflurane group than the propofol group (TLV: 1.39 vs. $1.23 \mathrm{mmol} \mathrm{L}^{-1}, p=0.063$; OLV15: 1.40 vs. $1.23 \mathrm{mmol} \mathrm{L}^{-1}, p=0.051$; OLV45: 1.42 vs. $1.21 \mathrm{mmol} \mathrm{L}^{-1}$, $p=0.006$; for sevoflurane vs. propofol, respectively, Bonferroni correction) (Table 2). $\mathrm{DO}_{2}$ was not correlated with $\mathrm{SaO}_{2}(\mathrm{r}=0.09, p=0.100$, Figure 3; sevoflurane group, $\mathrm{r}=0.02$; propofol group, $\mathrm{r}=0.16)$.

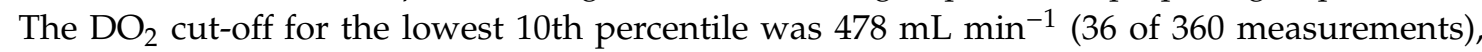
while the mean $\mathrm{SaO}_{2}$ was $97.5 \%$ for the lowest 10th percentile. Using a $\mathrm{DO}_{2}$ cut-off of $500 \mathrm{~mL} \mathrm{~min}{ }^{-1}$, in accordance with previous studies [7,8], 52 of 360 measurements (14\%) were lower than $500 \mathrm{~mL} \mathrm{~min}^{-1}$, and the mean $\mathrm{SaO}_{2}$ was $97.6 \%$ for those measurements. The lowest $\mathrm{DO}_{2}$ was $255 \mathrm{~mL} \mathrm{~min}^{-1}$, and the $\mathrm{SaO}_{2}$ was $98.7 \%$ at that point. $\mathrm{DO}_{2}$ was well-maintained at $641 \mathrm{~mL} \mathrm{~min}^{-1}$ in patients with $\mathrm{SaO}_{2}<94 \%$ (21 of 360 measurements) (Table 3).

Table 3. Relationship between $\mathrm{DO}_{2}$ and $\mathrm{SaO}_{2}$.

\begin{tabular}{ccc}
\hline Categories & Mean $\mathrm{DO}_{2}$ & Mean $\mathbf{S a O}_{2}$ \\
\hline $\mathrm{DO}_{2}$, at $<$ lower 10th percentile & $412 \pm 52$ & $97.5 \pm 2.3$ \\
$\mathrm{DO}_{2}$, at $<500$ mL min & -1 \\
$\mathrm{DO}_{2}$, at the lowest & $435 \pm 56$ & $97.6 \pm 2.2$ \\
$\mathrm{DO}_{2}$, at $\mathrm{SaO}_{2}<94 \%$ & 255 & 98.7 \\
\hline
\end{tabular}

The data are presented as mean \pm standard deviation.

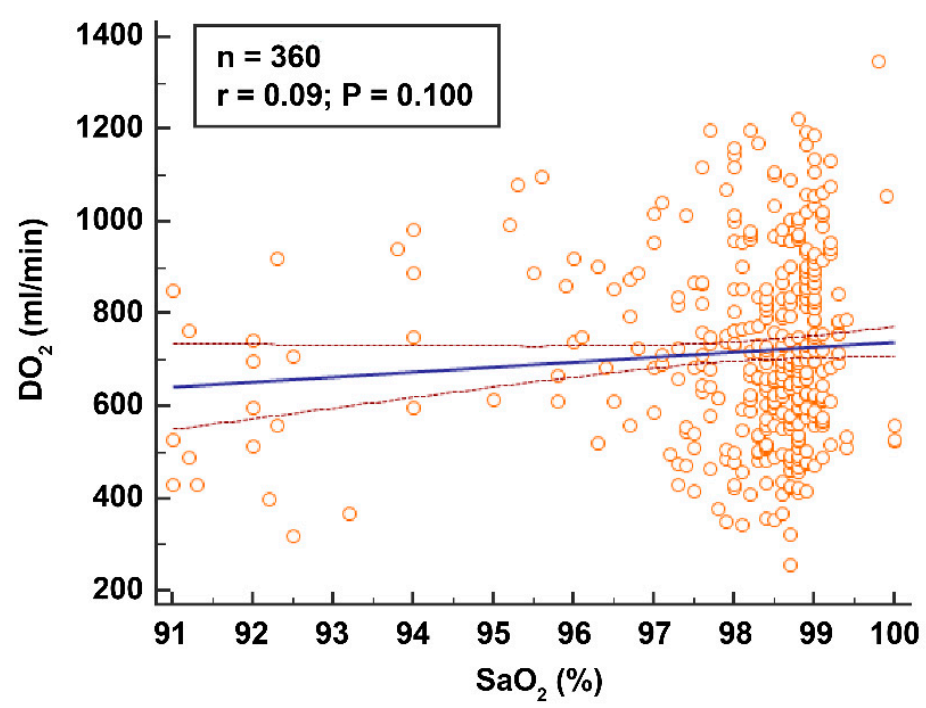

Figure 3. $\mathrm{DO}_{2}$ was not correlated with $\mathrm{SaO}_{2}(\mathrm{r}=0.09, p=0.100)$. Lines are a regression line with $95 \%$ confidence intervals. A dot is each measurement $(n=360)$. TLV, two lung ventilation; OLV15, 15 min after initiation of one-lung ventilation; OLV45, $45 \mathrm{~min}$ after initiation of one-lung ventilation.

\section{Discussion}

In this study, we found no difference in $\mathrm{DO}_{2}$ between sevoflurane- and propofol-based anaesthesia. Furthermore, $\mathrm{SaO}_{2}$ was not correlated with, and did not reflect the level of, $\mathrm{DO}_{2}$.

Sevoflurane and propofol, the two most commonly used anaesthetics, have previously been compared in terms of $\mathrm{SaO}_{2}$, but not in terms of $\mathrm{DO}_{2}$, during OLV [9]. $\mathrm{DO}_{2}$ reflects the circulation and oxygenation status, and it is increasingly being used in critical care [4]. Our study is the first to measure $\mathrm{DO}_{2}$ during OLV and to investigate whether $\mathrm{DO}_{2}$ differs according to the anaesthetic used. 
Previously, inhalation anaesthetics, including sevoflurane, were thought to reduce hypoxic pulmonary vasoconstriction $[10,11]$, thereby increasing the 'shunting' of nonoxygenated blood during OLV and, thus, causing lower $\mathrm{SaO}_{2}$ [12]. In the current study, there was no difference between the two anaesthetic groups in the alveolar-arterial $\mathrm{O}_{2}$, which reflects pulmonary shunting. Therefore, our results are consistent with the findings of previous reports, which suggested that sevoflurane and propofol had similar effects on shunt fraction [17] and $\mathrm{SaO}_{2}$ [9] during OLV.

Cardiac output was not different between the two groups in this study. Previous studies reported inconsistent results regarding cardiac output in association with sevoflurane and propofol [14-16,18]. One study showed that when the anaesthetic was titrated to $\sim 1$ minimum alveolar concentration (MAC) to maintain the BIS between 40 and 60, the cardiac-suppressive effect was negligible [16]. Cardiac output subsequently increased during OLV in both groups in our study. Therefore, the increase in $\mathrm{DO}_{2}$ with time seems to be due to the increase in cardiac output over time.

The lack of difference in $\mathrm{DO}_{2}$ between our groups may be explained by the lack of difference in shunt amount and cardiac output between the two anaesthetics at 1 MAC and BIS 40-60.

In a normal $75 \mathrm{~kg}$ adult partaking in low-intensity daily activities, the amount of $\mathrm{O}_{2}$ consumption $\left(\mathrm{VO}_{2}\right)$ is approximately $250 \mathrm{~mL} \mathrm{~min}{ }^{-1}$ [5]. During anaesthesia, $\mathrm{VO}_{2}$ was reported to be $175 \mathrm{~mL}$ $\mathrm{min}^{-1}$ in one study [19]. However, $\mathrm{VO}_{2}$ varies considerably among patients, as well as over time, during anaesthesia $[7,8]$. In a recent meta-analysis, $\mathrm{VO}_{2}$ was shown to decrease (by $-65 \mathrm{~mL} \mathrm{~min}{ }^{-1}$ ) from baseline following the induction of anaesthesia. Moreover, it increased after surgical incision and during the postoperative period [20]. Shibutani et al. [6] suggested that a $\mathrm{DO}_{2}$ of at least $330 \mathrm{~mL} \mathrm{~min}^{-1}$ is required under anaesthesia to prevent tissue $\mathrm{O}_{2}$ deprivation. Skykes et al. [7,8] suggested that anaesthetists using low flows should aim for a $\mathrm{DO}_{2}$ closer to $500 \mathrm{~mL} \mathrm{~min}^{-1}$, which should also be the target in emergency situations. In high-risk patients undergoing major noncardiac surgery, the critical threshold for $\mathrm{DO}_{2}$ was reported as $390 \mathrm{~mL} \mathrm{~min}^{-1} \mathrm{~m}^{2-1}$ during anaesthesia [21]. We found that $\mathrm{DO}_{2}$ was generally maintained above $500 \mathrm{~mL} \mathrm{~min}^{-1}$ during $\operatorname{OLV}\left(693,694\right.$, and $770 \mathrm{~mL} \mathrm{~min}^{-1}$ at TLV, OLV15, and OLV45, respectively).

There was no correlation between $\mathrm{SaO}_{2}$ and $\mathrm{DO}_{2}\left(\mathrm{r}=0.09, p=0.100\right.$, Figure 3). $\mathrm{DO}_{2}$ was maintained at $641 \mathrm{~mL} \mathrm{~min}^{-1}$ in patients with $\mathrm{SaO}_{2}<94 \%$. Importantly, a high $\mathrm{SaO}_{2}$ does not guarantee that a patient is receiving adequate $\mathrm{DO}_{2} ; 14 \%$ of our $\mathrm{DO}_{2}$ measurements were below $500 \mathrm{~mL} \mathrm{~min}{ }^{-1}$, which was regarded as the safety cut-off in previous studies [7,8]. The mean $\mathrm{SaO}_{2}$ was $97.6 \%$ for those measurements. The mean $\mathrm{SaO}_{2}$ was $97.5 \%$ in the lowest 10 th percentile of $\mathrm{DO}_{2}$ (cut-off: $412 \mathrm{~mL} \mathrm{~min}{ }^{-1}$ ). Based on the maximum oxygen extraction ratio $(70 \%)$, patients in the lowest 10th percentile of $\mathrm{DO}_{2}$ are in the "danger zone" [5]. In our study, the $\mathrm{SaO}_{2}$ was $98.7 \%$ at the lowest $\mathrm{DO}_{2}\left(255 \mathrm{~mL} \mathrm{~min}^{-1}\right)$.

If accompanied by high $\mathrm{DO}_{2}$, low $\mathrm{SaO}_{2}$ usually arises from increased cardiac output and subsequently increased pulmonary shunt during thoracic surgery. Therefore, a low $\mathrm{SaO}_{2}$ does not result in inadequate oxygen delivery if the cardiac output and $\mathrm{DO}_{2}$ are well maintained [5]. Our results support the necessity of measurement of $\mathrm{DO}_{2}$ during OLV.

In this study, the plasma lactate level was higher with sevoflurane than with propofol. The aetiology of this difference is unclear, but it may have been related to the tendency towards a lower stroke volume in the sevoflurane group than in the propofol group. Lactate is a metabolite associated with inadequate $\mathrm{DO}_{2}$ to tissues and is, therefore, widely used as a surrogate for tissue hypoxia. $\mathrm{DO}_{2}$ reflects haemodynamics and real-time systemic oxygen delivery. Therefore, $\mathrm{DO}_{2}$ and lactate can be used to complement each other.

This study had several limitations. Firstly, we used oesophageal Doppler monitoring to measure cardiac output instead of the thermodilution technique. However, a pulmonary artery catheter is rarely used for thoracic surgery, while oesophageal Doppler monitoring has high validity for determining changes and trends in cardiac output and is closely correlated with pulmonary artery catheter and echocardiography data [22-24]. However, $\mathrm{DO}_{2}$ is calculated based on cardiac output values on oesophageal Doppler monitoring, and uncertainties in the cardiac output measurements may have influenced the results. Secondly, $\mathrm{DO}_{2}$ represents global oxygen delivery, and not tissue 
oxygen delivery specifically. However, if patients do not have microcirculation or cellular oxygen uptake abnormalities, which are typically observed in severe vascular disease or sepsis, $\mathrm{DO}_{2}$ closely reflects tissue oxygen delivery. Thirdly, we excluded patients with severe pulmonary or cardiovascular dysfunction. Haemodynamic suppression may be more severe, and pulmonary shunt may show a greater increase by anaesthesia in these patients; the effect may be different between sevoflurane and propofol. This study is the first to measure $\mathrm{DO}_{2}$ change during OLV in relatively healthy patients. Based on our results, future studies with more seriously ill patients should be possible.

\section{Conclusions}

In this study, the type of anaesthetic (propofol or sevoflurane) did not have a significant impact on $\mathrm{DO}_{2}$. Furthermore, we found no correlation between $\mathrm{SaO}_{2}$ and $\mathrm{DO}_{2} \cdot \mathrm{DO}_{2}$ data may provide useful additional information on patient status, especially in those with a low $\mathrm{SaO}_{2}$ level.

Author Contributions: Conceptualization, T.S.H., H.J. and H.J.A.; Investigation, T.S.H., H.J. and H.J.A.; Methodology, T.S.H., H.J. and H.J.A.; Project administration, T.S.H., H.J. and H.J.A.; Supervision, H.J.A.; Writing—original draft, T.S.H., H.J. and H.J.A.; Writing—review \& editing, T.S.H., H.J. and H.J.A.

Acknowledgments: We thank Jae Woon Jeong, a medical student of Chung-Ang University for helping with data management.

Conflicts of Interest: The authors declare no conflict of interest.

\section{References}

1. Ackland, G.L.; Iqbal, S.; Paredes, L.G.; Toner, A.; Lyness, C.; Jenkins, N.; Bodger, P.; Karmali, S.; Whittle, J.; Reyes, A.; et al. Individualised oxygen delivery targeted haemodynamic therapy in high-risk surgical patients: A multicentre, randomised, double-blind, controlled, mechanistic trial. Lancet Respir. Med. 2015, 3, 33-41. [CrossRef]

2. Pinsky, M.R. Hemodynamic evaluation and monitoring in the ICU. Chest 2007, 132, 2020-2029. [CrossRef]

3. Bihari, D.; Smithies, M.; Gimson, A.; Tinker, J. The effects of vasodilation with prostacyclin on oxygen delivery and uptake in critically ill patients. N. Engl. J. Med. 1987, 317, 397-403. [CrossRef]

4. Perel, A. Non-invasive monitoring of oxygen delivery in acutely ill patients: New frontiers. Ann. Intensive Care 2015, 5, 24. [CrossRef]

5. Leach, R.M.; Treacher, D.F. The pulmonary physician in critical care *2: Oxygen delivery and consumption in the critically ill. Thorax 2002, 57, 170-177. [CrossRef]

6. Shibutani, K.; Komatsu, T.; Kubal, K.; Sanchala, V.; Kumar, V.; Bizzarri, D.V. Critical level of oxygen delivery in anesthetized man. Crit. Care Med. 1983, 11, 640-643. [CrossRef]

7. Sykes, O. Oxygen monitoring during low flow anaesthesia. J. Clin. Monit. Comput. 2010, 24, 141. [CrossRef]

8. Sykes, O. Metabolic oxygen requirements. Anaesthesia 2017, 72, 415-416. [CrossRef]

9. Pruszkowski, O.; Dalibon, N.; Moutafis, M.; Jugan, E.; Law-Koune, J.D.; Laloe, P.A.; Fischler, M. Effects of propofol vs. sevoflurane on arterial oxygenation during one-lung ventilation. Br. J. Anaesth. 2007, 98, 539-544. [CrossRef]

10. Marshall, C.; Lindgren, L.; Marshall, B.E. Effects of halothane, enflurane, and isoflurane on hypoxic pulmonary vasoconstriction in rat lungs in vitro. Anesthesiology 1984, 60, 304-308. [CrossRef]

11. Kellow, N.H.; Scott, A.D.; White, S.A.; Feneck, R.O. Comparison of the effects of propofol and isoflurane anaesthesia on right ventricular function and shunt fraction during thoracic surgery. Br. J. Anaesth. 1995, 75, 578-582. [CrossRef]

12. Abe, K.; Mashimo, T.; Yoshiya, I. Arterial oxygenation and shunt fraction during one-lung ventilation: A comparison of isoflurane and sevoflurane. Anesth. Analg. 1998, 86, 1266-1270.

13. Potočnik, I.; Novak Janković, V.E.S.N.A.; Štupnik, T.; Kremžar, B. Haemodynamic changes after induction of anaesthesia with sevoflurane vs. propofol. Signa Vitae J. Intesive Care Emerg. Med. 2011, 6, 52-57. [CrossRef]

14. Fujita, Y.; Yamasaki, T.; Takaori, M.; Sekioka, K. Sevoflurane anaesthesia for one-lung ventilation with PEEP to the dependent lung in sheep: Effects on right ventricular function and oxygenation. Can. J. Anaesth. 1993, 40, 1195-1200. [CrossRef] 
15. Filipovic, M.; Wang, J.; Michaux, I.; Hunziker, P.; Skarvan, K.; Seeberger, M.D. Effects of halothane, sevoflurane and propofol on left ventricular diastolic function in humans during spontaneous and mechanical ventilation. Br. J. Anaesth. 2005, 94, 186-192. [CrossRef]

16. Longnecker, D.E.; Tinker, J.H.; Morgan, G.E. Pharmacology of inhalational anesthetics. In Principles and Practice of Anesthesiology, 2nd ed.; Mosby: St. Louis, MO, USA, 1998.

17. Beck, D.H.; Doepfmer, U.R.; Sinemus, C.; Bloch, A.; Schenk, M.R.; Kox, W.J. Effects of sevoflurane and propofol on pulmonary shunt fraction during one-lung ventilation for thoracic surgery. Br. J. Anaesth. 2001, 86, 38-43. [CrossRef]

18. Ahn, J.H.; Ahn, H.J.; Yi, J.W. Total Intravenous anesthesia maintained the degree of pre-existing mitral regurgitation better than isoflurane anesthesia in cardiac surgery: A randomized controlled trial. J. Clin. Med. 2019, 8, 1104. [CrossRef]

19. Ritchie-McLean, S.; Shankar, R. Calculating oxygen consumption during low-flow anaesthesia. Anaesthesia 2017, 72, 789. [CrossRef]

20. Jakobsson, J.; Vadman, S.; Hagel, E.; Kalman, S.; Bartha, E. The effects of general anaesthesia on oxygen consumption: A meta-analysis guiding future studies on perioperative oxygen transport. Acta Anaesthesiol. Scand. 2019, 63, 144-153. [CrossRef]

21. Lugo, G.; Arizpe, D.; Dominguez, G.; Ramirez, M.; Tamariz, O. Relationship between oxygen consumption and oxygen delivery during anesthesia in high-risk surgical patients. Crit. Care Med. 1993, 21, 64-69. [CrossRef]

22. DiCorte, C.J.; Latham, P.; Greilich, P.E.; Cooley, M.V.; Grayburn, P.A.; Jessen, M.E. Esophageal Doppler monitor determinations of cardiac output and preload during cardiac operations. Ann. Thorac. Surg. 2000, 69, 1782-1786. [CrossRef]

23. Dark, P.M.; Singer, M. The validity of trans-esophageal Doppler ultrasonography as a measure of cardiac output in critically ill adults. Intensive Care Med. 2004, 30, 2060-2066. [CrossRef]

24. Laupland, K.B.; Bands, C.J. Utility of esophageal Doppler as a minimally invasive hemodynamic monitor: A review. Can. J. Anaesth. 2002, 49, 393-401. [CrossRef]

(C) 2019 by the authors. Licensee MDPI, Basel, Switzerland. This article is an open access article distributed under the terms and conditions of the Creative Commons Attribution (CC BY) license (http://creativecommons.org/licenses/by/4.0/). 